\title{
Editorial Responsibilities
}

(c) 2018. This is an Open Access article distributed under the terms of the Creative Commons-AttributionNoncommercial-Share Alike License 4.0 International (http://creativecommons.org/licenses/by-nc-sa/4.0/), which permits unrestricted use, distribution, and reproduction in any medium, provided the original work is properly attributed, not used for commercial purposes, and, if transformed, the resulting work is redistributed under the same or similar license to this one.

Editor-in-Chief: Lorie Kloda

Associate Editor (Evidence Summaries): Carol Perryman, Heather Pretty

Associate Editor (Research Articles): Ann Medaille, Lisl Zach

Associate Editor (Classics \& Reviews): Christina Wissinger

Associate Editor (Commentaries, Feature, Using Evidence in Practice): Lorie Kloda

Communications Officer (News): Tatiana Bryant

Production Editor: Michelle Dunaway, Rachel Hinrichs

Editorial Intern: Rachel Hinrichs, Kimberly MacKenzie

Editorial Advisors: Lindsay Alcock, Alison Brettle, Jonathan Eldredge, Denise Koufogiannakis

Copyeditors: Richard Hayman (Lead Copyeditor), Georgianne Bordner, Julie Evener, Heather Healy, Julie James, Emily Kingsland, Alison Moore, Jane Morgan-Daniel, Elizabeth Stregger, Elaina Vitale

Indexing Support: Kate Shore 